Article

\title{
Statistical Properties of a New Social Media Context Awareness Scale (SMCA)— A Preliminary Investigation
}

\author{
Dana Rad ${ }^{1, *(\mathbb{D})}$, Valentina Balas ${ }^{2, *} \mathbb{D}$, Ramona Lile ${ }^{3, *}$, Edgar Demeter ${ }^{4, *}$, Tiberiu Dughi ${ }^{4, *}$ and \\ Gavril Rad ${ }^{4, *}$
}

1 Faculty of Educational Sciences, Aurel Vlaicu University of Arad, 310130 Arad, Romania

2 Faculty of Engineering, Aurel Vlaicu University of Arad, 310130 Arad, Romania

3 Faculty of Economics, Aurel Vlaicu University of Arad, 310130 Arad, Romania

4 Faculty of Educational Sciences, Psychology and Social Work, Aurel Vlaicu University of Arad, 310130 Arad, Romania

* Correspondence: dana@xhouse.ro (D.R.); valentina.balas@uav.ro (V.B.); ramona.lile@uav.ro (R.L.); edgar.demeter@uav.ro (E.D.); tiberiu.dughi@uav.ro (T.D.); radgavrilarad@gmail.com (G.R.); Tel.: +40727803036, (D.R.); +40740059151 (V.B.); +40741100135 (R.L.); +40733056746 (E.D.); +40723683993 (T.D.); +40799372506 (G.R.)

Received: 17 May 2020; Accepted: 22 June 2020; Published: 25 June 2020

\begin{abstract}
In the Internet of Things era, or in the digitalization and mediatization of everything paradigm, where context awareness computing is on the rise, people are also facing a new challenge, that of being aware of the digital contexts, in all situations when surfing the internet's ocean of row information. The emerging social media context awareness competency refers to a new emerging skill regarding the trust load people give to a specific social media context they encounter. Since it is an emergent competence, it cannot be understood as standalone. If the digital context would not be available, we would not develop such a competence. Being a competence, it must be defined by three core elements: Knowledge, skills, and attitudes. Consequently, we have operationalized the competence of social media context awareness in terms of social media literacy, social media communication process understanding, social media content impact awareness, and social media confidence. An online questionnaire was created under the Erasmus+ project Hate's Journey, addressing a convenience sample of 206 online youth respondents from Turkey, Spain, Latvia, and Romania. Our team has computed a reliability analysis on the social media context awareness scale designed with four items referring to social media literacy $(\mathrm{m}=3.79, \mathrm{SD}=1)$, social media communication process understanding $(\mathrm{m}=3.77, \mathrm{SD}=0.9)$, social media content impact awareness $(\mathrm{m}=3.88, \mathrm{SD}=1)$, and social media confidence $(\mathrm{m}=3.45, \mathrm{SD}=1)$. Cronbach's alpha coefficient and the Exploratory Factor Analysis demonstrated the acceptable reliability of the SMCA scale, $\alpha=0.87$. Conclusions, implications, and limitations are discussed in the context of social sustainability.
\end{abstract}

Keywords: social sustainability; emerging digital competency; mediatization of everything; social media context awareness; social media literacy; social media communication process understanding; social media content impact awareness; social media confidence

\section{Introduction}

The context awareness concept has been firstly developed by Schilit and Theimer in 1994 [1] and a few years later, Ryan et al. [2] described and defined it. In both instances, computer algorithms and systems were the object of their research. As described by Abowd et al. in 1999 [3], the term context can be defined as any information that can be used to characterize the situation of an entity. In this light, 
an entity can be an individual, a location, or an object that is suited to be important to the interaction between a user and an application [3]. Context awareness is described as an ability of the computer to identify information about its surroundings (i.e., location, time, and temperature or user identity) and act upon it [2]. In other words, the term context awareness has therefore been described by Dey et al. in 2001 [4] as a device utilizing context to offer appropriate knowledge and/or resources to the consumer, where importance of the process depends on the role of the consumer [3].

In computer science, once a system is evaluated, it can be conveniently determined whether that specific device is a system with context awareness or not $[5,6]$, as regards to the investigated concept. Frameworks for context awareness will usually help development, description, execution, and response [4]. In this light, there are three main approaches [7] that can be followed to build context aware systems:

1. No framework-level context model: Programs conduct certain operations within the boundaries of the application, such as context extraction, preprocessing, storage, and reasoning.

2. Implicit framework model: Databases, structures, and toolkits are used by programs to execute context acquisition, preprocessing, retrieval, and reasoning functions. It provides a standard interface which makes the design far simpler to create and the context is always loosely related to the application.

3. Explicit context model: Middleware or context management frameworks are used by applications. Operations such as: Context acquisition, preprocessing, storage, and reasoning also fall beyond the application's limits. Context control and application are distinctly different and might be designed and extended separately.

The digital world and its mechanics are a vast one and our focus in this article, from the entire digital context, will be the social media part and how users interact with it. Social media is represented by the use of technologies (i.e., personal computers, smart phones, tablets) that facilitate the production or sharing of content $[8,9]$. Common features that can be found through social media platforms are represented by: Content created and shared by users (i.e., comments, ideas, photos, and videos) and by social networking $[8,9]$.

Our focus in this article regarding the social media context awareness will be on: The ability to access information on social media, the awareness of the creation and sharing of content on social media, the awareness of third party applications in relation to social media, and the ability and impulse to create and share content on social media.

The ability to access information on social media can be important and practical for an individual if he or she is looking for a job or career [10]. For example, a social media platform such as LinkedIn can offer various processes (i.e., keyword searches or information feeds) to obtain information regarding career opportunities [10]. Another practical implication for the ability to access information on social media that can be important for an individual is if he or she is looking for travel opportunities. For example, social media platforms that focus on traveling and tourism can offer significant information (i.e., cost comparisons, user reviews, housing services, locations, shared photos, and videos) to users regarding traveling opportunities [11].

This research is consistent with presenting a view focused on media and cultural sustainability study of interactions and social practices, a mediatization and culturalization of sustainability $[12,13]$.

A current mediatization analysis [14-20] has demonstrated how the mediatization mechanism affects the role of the media in framing, defining context, and shaping contemporary cultures marked by mediatization of everything $[18,21]$. The concept of social media context awareness is deeply rooted into the mediatization paradigm. Each information that is mediatized in the social media environment has its own purpose and nowadays we witness a race towards creating and sharing new social media content. Of course, since recipients of social media content are not always equipped with critical thinking skills in order to avoid the fake news trap or other forms of misinformation and disinformation. The first step in starting to sort and filter different social media information is the 
ability of being aware of the social media context. Individuals need to frame all information that they meet on social media, in order to better understand the meaning of that particular information.

The transdisciplinary essence of the recent global interest in the analysis of social sustainability mediatization encompasses and incorporates the common need for social sciences to challenge and respond to the need to rethink the framework itself on clarity and perception of the climate, culture, and the economy. Media's portrayal of social sustainability in line with the spirit of the advent of social media and new information and communication technologies sets up a major cognitive discontinuity into the democratic and scientific debate, with truly little consideration. This poses several concerns, on the one side, of a political aspect, but more often of an intellectual, epistemological, and empirical sort, and, on the other, of providing empirical significance in other fields of knowledge such as information and communication sciences, sociology, politics, law, administrative sciences, economics, psychology, etc.

The digital psychology domain looks further into online behaviors, with the purpose of offering an explanation as to why digital participants behave in a specific manner. In the case of better understanding the behaviors in the digital realm, people can better understand how to digitally position themselves towards a digital event and most of all to promote digital wellbeing [22,23].

Based on previous research [23], we define social media context awareness as an emerging digital skill referring to the understanding of the social media environment in which a specific event takes place, acknowledging the impact that the perceived social media context has over the observer, rationalizing the social media informational undergoing process, and owning confidence for social media acting.

Consequently, we have operationalized the competence of social media context awareness in terms of digital literacy, digital communication process understanding, digital content impact awareness, and digital confidence.

The rest of the section will describe one by one the four components of the emerging social media context awareness competency and will further bring research evidence on the importance of the evidence-based validation of this new digital skill, social media context awareness.

Digital literacy is loosely described in the scientific literature, merely as a question of technological competence [24]. This paper's vision is in favor of a concept of digital literacy that surpasses any of the strategies pursued in education in information technology, namely implicit is no longer an efficient approach. Digital media may no longer easily be viewed as information or technologies.

Computers are far more than tools for the processing of knowledge in most young people's leisure-time experiences: They transmit pictures and dreams, provide possibilities for creative expression of the self and play, and act as a means by which close interpersonal relations are performed. Such technologies can no longer be interpreted if we merely choose to view them as a question of devices and methods, or as hardware and software.

Eshet-Alkalai [25] argues that indistinct terminology creates confusion and conducts to inconsistency, inadequate communication, and instability, and also that there is a clear difference between people who believe that digital literacy is mainly associated with computational capabilities and others that perceive it as concentrated on socio-affective and cognitive dimensions of digital functioning. Although a number of analysts used the term of digital literacy in Gilster's perspective throughout this time [26], a specific concept focused on the aggregation of knowledge from various outlets and critical thinking, some authors equivalent it with machine literacy, concentrating on IT abilities as an element of the vaster information literacy concept [27], whilst other scholars contrasted it with network literacy centered on the optimal usage of the digital resources variety [28].

Another researcher, Burniske [29] uses it as a term that relies extensively on the critical thinking dimension, taking into account: Deliberate and ethical usage of the language; logical website assessment; web-based digital content analysis; examination of digital material for authenticity, reasoning and embedded emotional content, and the netiquette. 
In a similar manner, Martin [30] presents e-literacy as a core concept, having three interconnected dimensions: a) Information connectivity, b) information interaction, and c) information utilization.

In a somewhat related way, [25] defines a modern philosophical paradigm for digital literacy as a crucial ability of the digitalization age, though primarily taken from the sense of formal education and mostly relevant to it, based on five integrated literacies: 1 . Visual literacy or visual representational understanding; 2. reproduction literacy or imaginative reuse of available resources; 3 . information literacy or information assessment; 4 . decomposition literacy or the capability to observe and grasp hypermedia; and 5. socio-affective literacy or positive, responsive actions in digital space.

We may mention the fact that what has been widely thought as the core focus of digital literacy, the capacity to synthesize and incorporate knowledge from a range of resources, is gaining greater recognition as a critical skill, in areas of research very distant from those in which digital literacy is studied.

Finally, the perceptions and viewpoints illustrate the fact that the overarching aim of digital literacy is to assist persons in understanding what is important for their specific case. Social or moral literacy reflects the need to consider sensible and correct actions in the digital environment, which can involve privacy with protection concerns. In this light, core concepts must focus on understanding, meaning, and context [31-33]. It may not be irrational to see this literacy as an integral prerequisite of existence in a digital era, articulated correctly according to the context.

Referring to the definition of media literacy, it is described as the ability to recognize various forms of media and to interpret the message they deliver. Text updates, photos, YouTube stories, social media, computer games, ads, etc., all the media have one thing in common: Somebody invented it for a cause. Understanding that is the foundation of media literacy. The digital era made it possible for everyone to design, build, post, share, and integrate media. In most cases, people do not really know who produced the social media content, why it was made, and if it is reliable, this knowledge is thus difficult to learn, still media literacy is becoming an essential skill in the digital age. With the emergence of extreme automation of news sources, content flows, and search queries, it has become exceedingly difficult to locate reliable, impartial online content. Such modern online worlds need very basic literacy abilities from their consumers in order to be completely in charge of their online identity and to make the best of the resources that these emerging technology and online social media platforms have to bring, while at the same time minimizing risks.

Social media literacy (SML) [34-38] can be described as a collection of competences that empowers people to obtain, download, recognize, analyze and utilize, generate and exchange knowledge and media content in all forms, use different resources in a vital, ethical, and efficient way to participate and engage in personal, professional, and community activities. This implies that a media and technology literate individual must not only be a consumer of technology and media material, but also a conscientious source of information, a developer of awareness, and an innovator who can make use of a broad variety of information and communication technologies and media. Therefore, SML may be interpreted as a broad collection of technological, cognitive, and emotional skill sets that are needed in the quest for knowledge, communication, content production, and problem-avoiding and problem-solving in social media, both in social and professional frameworks. To get individuals engaged and be informed citizens, they must become critical and independent thinkers and active content creators, rather than passive online content and technology consumers.

Nevertheless, SML is not a single-dose drug, nor is it a miracle-all cure remedy. Although online problems share several parallels, each group experiences various forms of concerns that may vary from cyberbullying to misinformation, posting offensive material or radicalization, etc. That is why, an awareness of the social media context becomes a vital skill to all.

Related to social media communication process understanding, we can relate the same argument as above.

As related to social media content impact awareness, new research conclusions bring evidence to the relevant importance of this concept. Human activities and experiences on social media have 
remained extremely complex real-time social networks reflecting human social awareness in all possible environments [39].

Ambient awareness relates to the awareness that digital consumers are developing over their digital network as an output of being continuously immersed in social updated knowledge [40]. Even if each specific piece of knowledge can sound as a meaningless noise, its incessant processing will lead to a cohesive reflection of others in society. Despite the visibility enhancement and crucial consequences for social-media studies, there has been no empirical analysis of ambient awareness of public social media, the only peer-reviewed published studies reflect educational settings only.

Related to digital confidence, we would like to underline some findings that support our understanding of the concept. The digital divide [41] is of special significance in the health and social care frameworks [42].

While scholars have begun to examine the influence of the Internet on users' preferences and even personality, there is little research that explores the unique effect of the social media, thus its social impact remains unclear. One of the main conclusions of this research is that there is a paucity of peer-reviewed studies testing the effect of social media context awareness on digital behaviors [43]. One of the first peer-reviewed studies that has been reported on the topic is that of Kalaivani and Bakkiyalashmi [44], who have designed a social media awareness scale, aiming to study the awareness and utilization of social media in an educational setting. The Social Media Awareness scale and the social media utilization scale are found to be in a positive relationship, although no references are given related to items used, subscales, internal consistency, or scale reliability. A second reported study on the topic of social media context awareness [45], has investigated the level of experience and understanding of social media, again in an educational setting. The validity and reliability of such measures were established in a previous study on computer understanding and experience [46]. The 12 items questionnaire used in this research are similar to questions that have been used in previous studies to assess digital technology experience (six items) and understanding (six items) [47]. Some of the items were modified to fit the study's objective.

As far as we are aware, none of the previous research studies have investigated users' attitude towards using social media platforms, namely the confidence level they feel when connecting and interacting in the digital environment. Moreover, previous studies have only investigated the human-computer awareness interaction in educational settings, not for the general population, using short scales comprised of maximum of 12 items.

This study begins to fill this research gap by designing and validating a short version of the social media context awareness scale that can be used for general assessment.

The emergence of the four constructs of digital literacy, digital communication process understanding, digital content impact awareness, and digital confidence creates a need for explicit measures of social media context awareness, with regards to the principle of consistency in digital behavior; some researchers consider acting to be consistent across social media [48]. If behavioral consistency refers to people's tendency to behave in a manner that matches their past decisions or behaviors [49], the digital behavioral consistency refers to the same tendencies, but in the digital environment.

The analysis findings suggest that environmental awareness will grow on the outskirts, from scattered knowledge, and in the relative absence of robust one-to-one contact, depending on factors such as demographics, media consumption, and network options [40].

\section{Materials and Methods}

\subsection{Objective and Hypothesis}

The present mediatization work [14-20] has demonstrated how the mediatization process influences the role of the media in framing, constructing context, and changing contemporary cultures marked by the mediatization of everything $[18,21]$. Mediatization, used to objectively 
examine the interrelationship between shifts in communications and media, and shifts in culture and society [17], is especially important for social sustainability research. On the one hand, the focus of Tudor and Bratosin's research on the social aspect of sustainability connected to culturalisation understood culture as an intellectual, central, fundamental force in sustainability-based social processes and relationships, and on the other hand, considered the diffusion of culture [50]. A culture of mediatization will be in constant dynamics, with new media technologies mediating its principal properties. In this regard, research results have shown that mediatization is the product and effect of partnerships, interrelationships, interactions, and interconnections between society's use of communication mechanisms and technologies strengthened by modern technology and, at the same time, relates to a new social environment that is intensely centered on such partnerships, interrelationships, and connections that design the contemporary society [50].

The aim of this paper is to provide realistic metrics for calculating the efficacy and legitimacy of online survey response measures, evaluating individuals' social media context awareness. Reliability represents accuracy, and precision is given in validity. Thus, our aim is to calculate the reliability and validity of a preliminary short four items scale measuring social media context awareness (SMCA).

The social media context awareness competence refers to a new emerging skill regarding the trust load we give to a specific digital context we come in contact with when surfing the internet. Since it is an emerging competence, it cannot be understood as standalone. If the digital context would not be available, we would not develop such a competence. Being a competence, it must be defined by three core elements: Knowledge, skills, and attitudes, just as we operationalized the competence of social media context awareness in terms of: Social media literacy, social media communication process understanding, social media content impact awareness, and social media confidence.

\subsection{Participants}

Our research team has launched the project Hate's Journey sponsored by Erasmus+ to explore the experiences of the digital wellbeing correlates. Our research team has developed a multiple section specific online questionnaire that targets 206 young people from Turkey, Spain, Latvia, and Romania. A sample of 206 participants from Romania (a value of $24.8 \%$ ), Latvia (a value of $24.8 \%$ ), Spain (a value of $24.8 \%$ ), and Turkey (a value of $25.7 \%$ ), distinguished by an average age of 30, male respondents $(39.8 \%)$ and female respondents $(60.2 \%)$, with an educational ratio of $3.9 \%$ primary school, $1.9 \%$ professional school, 29.1\% high school, 32\% Bachelor degree, 29.1\% Master degree, and 3.9\% PhD level.

With respect to career rank, respondents who are unemployed constitute $5.8 \%$, graduates constitute $43.7 \%$, volunteers represent $1 \%$, and $49.5 \%$ are integrated into the labor market.

The internet time that respondents spend was rarely or almost ever $(1 \%)$, every week $(8.7 \%)$, nearly every day $(20.4 \%)$, many hours a day $(46.6 \%)$, and almost all the time $(23.3 \%)$. As a general picture, as opposed to non-users, the number of persistent internet users reaches $69.9 \%$.

This report has used convenience sampling or sequential sampling, owing to its explorative intent. On completion of the online questionnaire posted on social media platforms such as Facebook and LinkedIn, by each of the four project partner nations, each nation targeting at least 50 respondents, the number of participants being chosen was according to the order of appearance and according to the convenient accessibility principle. The sampling cycle stopped when each of the four participant countries on the project achieved sample saturation (50 participants) and period saturation (three months). Four agencies coordinated data collection procedures: Asociación Cultural Social y Educativa Segundas Oportunidades (Spain), Aurel Vlaicu University of Arad (Romania), Ucarli Genclik Dernegi (Turkey), and Young Folks (Latvia).

\subsection{Instruments}

With the purpose of designing and validating a new scale of social media context awareness (SMCA), we have operationalized the emerging digital skill as a confluence between four key components: Social media literacy, social media communication process understanding, social media 
content impact awareness, and social media confidence, in a preliminary attempt to uncover concepts association as a valid and reliable four factors scale.

The following research items were used:

- For social media literacy $(\mathrm{m}=3.79, \mathrm{SD}=1)$ assessment, this research used Item 1 . On a one to five scale where 1 stands for strongly disagree, 2 for disagree, 3 for neither agree nor disagree, 4 for agree, 5 for strongly agree, please rate how much you agree with the following sentence: I'm able to access the information and content I want on social media.

- For social media communication process understanding $(\mathrm{m}=3.77, \mathrm{SD}=0.9)$ assessment, this research used Item 2. On a one to five scale where 1 stands for strongly disagree, 2 for disagree, 3 for neither agree nor disagree, 4 for agree, 5 for strongly agree, please rate how much you agree with the following sentence: I understand how people create and spread messages on social media.

- For social media content impact awareness $(\mathrm{m}=3.88, \mathrm{SD}=1)$ assessment, this research used Item 3. On a one to five scale where 1 stands for strongly disagree, 2 for disagree, 3 for neither agree nor disagree, 4 for agree, 5 for strongly agree, please rate how much you agree with the following sentence: I understand the role social media websites/apps play in shaping the information and content I see.

- For social media confidence ( $\mathrm{m}=3.45, \mathrm{SD}=1)$ assessment, this research used Item 4 . On a one to five scale where 1 stands for strongly disagree, 2 for disagree, 3 for neither agree nor disagree, 4 for agree, 5 for strongly agree, please rate how much you agree with the following sentence: I'm confident creating and sharing my own social media messages.

\subsection{Study Design and Procedure}

Measurement requires awarding points to people such that they reflect specific human characteristics. We performed this analysis utilizing the online measure to confirm that the results are compatible based on our interpretation of the social media context awareness construct.

With respect to reliability, internal consistency relates to the accuracy of individual answers around the items on our assessment of SMCA. All four items would represent the same fundamental concept, and the scores of respondents on certain items will be associated with each other. If the individual's responses to the different items are not strongly associated among each other, then it would not be acceptable to assert that they all measure the same social media context awareness construct. The most famous indicator of internal accuracy used by psychology researchers is the Cronbach's alpha statistic. Conceptually for a group of objects $\alpha$ is the sum of all potential split-half associations. In general, a value of +0.80 or greater is taken to imply a strong internal consistency.

We will compute an exploratory factor analysis (EFA) to have a closer look at the latent theoretical structure of the social media context awareness and to underline the structure of the underlying relationships between measured variables. The exploratory factor analysis represents a multivariate statistical approach intended to promote the postulation of latent variables that are assumed to underlie association trends in different manifested variables domains. Intellectual abilities such as the social media context awareness are well-known types of latent variables and are the subject of EFA.

The degree to which our SMCA metric encompasses the concept of interest is content validity. In general, content validity is not assessed quantitatively, but is assessed by carefully evaluating the calculation process against the concrete definition of the concept. We define social media context awareness as an emerging digital skill referring to the understanding of the digital environment in which a specific event takes place, acknowledging the impact that the perceived social media context has over the observer, rationalizing the social media informational undergoing process, and owning confidence for social media acting.

Criterion validity reflects the degree to which the ratings of the respondent on the SMAS scale are associated with certain tests of understanding, defined as criteria, which one would assume to correspond with them. If the criteria are evaluated in conjunction with the construct, the validity of 
the criteria is considered concurrent validity. Therefore, the criteria can provide certain tests of the same construct as well. For instance, one would expect to find significant relations between recent measures of social media context awareness and current measures of the same specific psychological structures, recognized as convergent validity. Correlations are to be found between the SMCA scale and the mindful attention awareness scale (MAAS) [51,52]. MAAS is a scale of 15 items developed to measure a central attribute of mindfulness, a responsive state in which consciousness, guided by a conscientious knowledge of what is happening in the moment, merely observes what is occurring. We expect a high correlation coefficient between the two measures SMCA and MAAS.

\section{Results}

A reliability analysis was computed on the Social Media Context Awareness scale of four items referring to social media literacy "I'm able to access the information and content I want on social media" ( $\mathrm{m}=3.79, \mathrm{SD}=1)$, social media communication process understanding "I understand how people create and spread messages on social media" $(\mathrm{m}=3.77, \mathrm{SD}=0.9)$, social media content impact awareness "I understand the role social media websites/apps play in shaping the information and content I see" ( $\mathrm{m}=3.88, \mathrm{SD}=1)$, and social media confidence "I'm confident creating and sharing my own social media messages" $(\mathrm{m}=3.45, \mathrm{SD}=1)$.

In summary, the social media context awareness scale has a subcomponent mean of $\mathrm{m}=3.72$, with a minimum of $\mathrm{m}=3.45$ for the subcomponent social media confidence, a maximum of $\mathrm{m}=3.88$ for the subcomponent social media content impact awareness, a range of 0.42 , and a variance of 0.03 .

In terms of the SMCA scale statistics, we have obtained a mean of $\mathrm{m}=14.89$, a variance of 11.62 , and a standard deviation of $\mathrm{SD}=3.41$ for the four items. No statistically significant differences have been found based on gender or nationality.

Cronbach's alpha coefficient proves the questionnaire to achieve a reasonable precision, $\alpha=0.87$. The first three items appeared deserving of preservation, culminating in a decrease of the alpha if omitted. The only exception to that was Item 4 , bringing the alpha to $\alpha=0.91$. The elimination of this item has not been taken into consideration, even if the scale of three items would gain increased reliability with $3 \%$, because the social media confidence concept reflects a mandatory digital attitudinal output, the confidence of social media acting.

The Kaiser-Meyer-Olkin sampling adequacy test is a metric showing the amount of SMCA variation that may be induced by the underlying variables. High values displayed in Table 1, usually suggest the adequacy of the sampling.

Table 1. Social media context awareness (SMCA) item statistics.

\begin{tabular}{|c|c|c|c|c|c|}
\hline \multicolumn{6}{|c|}{ Item-Total Statistics } \\
\hline & $\begin{array}{l}\text { Scale Mean if } \\
\text { Item Deleted }\end{array}$ & $\begin{array}{l}\text { Scale Variance } \\
\text { if Item Deleted }\end{array}$ & $\begin{array}{l}\text { Corrected } \\
\text { Item-Total } \\
\text { Correlation }\end{array}$ & $\begin{array}{l}\text { Squared } \\
\text { Multiple } \\
\text { Correlation }\end{array}$ & $\begin{array}{l}\text { Cronbach's } \\
\text { Alpha if Item } \\
\text { Deleted }\end{array}$ \\
\hline $\begin{array}{l}\text { Item } 1 . \text { I'm able to access the } \\
\text { information and content I want } \\
\text { on social media. }\end{array}$ & 11.11 & 6.457 & 0.816 & 0.683 & 0.810 \\
\hline $\begin{array}{l}\text { Item 2. I understand how people } \\
\text { create and spread messages on } \\
\text { social media. }\end{array}$ & 11.13 & 6.706 & 0.793 & 0.718 & 0.820 \\
\hline $\begin{array}{l}\text { Item 3. I understand the role } \\
\text { social media websites/apps play in } \\
\text { shaping the information and } \\
\text { content I see. }\end{array}$ & 11.01 & 6.468 & 0.817 & 0.765 & 0.809 \\
\hline $\begin{array}{l}\text { Item } 4 . I^{\prime} m \text { confident creating } \\
\text { and sharing my own social media } \\
\text { messages. }\end{array}$ & 11.44 & 7.603 & 0.535 & 0.315 & 0.918 \\
\hline
\end{tabular}


The Chi-square estimate is 531.769 with six degrees of freedom, which is important at a threshold of 0.001 . The $0.785 \mathrm{KMO}$ statistics were also high (greater than 0.7 ) as seen in Table 2. Thus, the factor analysis is deemed as an appropriate methodology for further examination of the results.

Table 2. Kaiser-Meyer-Olkin (KMO) and Bartlett's test coefficients for SMCA.

\begin{tabular}{ccc}
\hline \multicolumn{3}{c}{ KMO and Bartlett's Test } \\
\hline Kaiser-Meyer-Olkin Measure of Sampling Adequacy & 0.785 \\
\hline \multirow{3}{*}{ Bartlett's Test of Sphericity } & Approx. Chi-Square & 531.769 \\
& Df & 6 \\
& Sig. & 0.000 \\
\hline
\end{tabular}

As related to the analysis of Eigen values, results presented in Table 3, the first components represent the numbers of the variables introduced in the FA. In the present research, four factors will be extracted. The variances of the factors are the Eigen values. The first element also accounts for the largest variation and thus has the maximum Eigen value. The next element must cover for as much of the variation left over as it can, and the process must happen until the last component. The percentage of variance reflects the percentage of overall variance that each element accounts for, and the combined percentage makes the current and previous element the cumulative percentage of the variance account. In the present analysis, the first component explains $73.89 \%$ of the variance, component 2 explains $16 \%$ of the variance, component 3 explains $6.28 \%$, and component 4 explains $3.82 \%$ of the variance.

Table 3. Total variance explained for SMCA.

\begin{tabular}{|c|c|c|c|c|c|c|c|c|c|}
\hline \multicolumn{10}{|c|}{ Total Variance Explained } \\
\hline \multirow{2}{*}{ Component } & \multicolumn{3}{|c|}{ Initial Eigenvalues } & \multicolumn{3}{|c|}{$\begin{array}{l}\text { Extraction Sums of Squared } \\
\text { Loadings }\end{array}$} & \multicolumn{3}{|c|}{$\begin{array}{l}\text { Rotation Sums of Squared } \\
\text { Loadings }\end{array}$} \\
\hline & Total & $\begin{array}{c}\% \text { of } \\
\text { Variance }\end{array}$ & $\underset{\%}{\text { Cumulative }}$ & Total & $\begin{array}{c}\% \text { of } \\
\text { Variance }\end{array}$ & $\begin{array}{c}\text { Cumulative } \\
\%\end{array}$ & Total & $\begin{array}{c}\% \text { of } \\
\text { Variance }\end{array}$ & $\begin{array}{c}\text { Cumulative } \\
\%\end{array}$ \\
\hline 1 & 2.956 & 73.891 & 73.891 & 2.956 & 73.891 & 73.891 & 1.078 & 26.948 & 26.948 \\
\hline 2 & 0.640 & 16.005 & 89.896 & 0.640 & 16.005 & 89.896 & 1.075 & 26.875 & 53.823 \\
\hline 3 & 0.251 & 6.284 & 96.180 & 0.251 & 6.284 & 96.180 & 0.986 & 24.652 & 78.475 \\
\hline 4 & 0.153 & 3.820 & 100.000 & 0.153 & 3.820 & 100.000 & 0.861 & 21.525 & 100.000 \\
\hline
\end{tabular}

The rotation procedure in summing of the squared loading represents the distribution of the variance following the promax rotation with Kaiser Normalization. The results are presented in Table 4, displaying loading of coefficients greater than 0.4 , with four factors. The principle of rotation is to decrease the numerical factors on which the investigated variables are highly loaded. Rotation simply does not alter something but allows the study to be easier for reading. Looking at Table 4, we can see that Item 1 is significantly loaded on Factor 3 while Item 2 is consistently loaded on Factor 2, and Item 4 is highly loaded on Factor 1 . We notice that Item 3 is substantially loaded on both Factor 2 and 4 , however we will opt for the higher loading of 0.775 , for Factor 4 . This dual loading might be explained by the fact that when defining the social media context awareness as a digital competence, we acknowledge it as a set of abilities, knowledge, and attitudes. Item 1 reflects a skill: Social media literacy; Items 2 and 3 reflect knowledge: Social media communication process understanding and social media content impact awareness; and Item 4 reflects an attitude: Social media confidence. 
Table 4. Rotated component matrix for SMCA.

\begin{tabular}{ccc}
\hline Rotated Component Matrix & \\
\hline & \multicolumn{3}{c}{ Component } \\
\cline { 2 - 3 } $\begin{array}{c}\text { social media. } \\
\text { stem 1. I'm able to access the information and content I want on } \\
\text { social media. }\end{array}$ & $\mathbf{2}$ & $\mathbf{3}$ \\
\hline $\begin{array}{c}\text { Item 2. I understand how people create and spread messages on } \\
\text { Item 3. I understand the role social media websites/apps play in } \\
\text { shaping the information and content I see. }\end{array}$ & 0.831 \\
\hline $\begin{array}{c}\text { Item 4. I'm confident creating and sharing my own social } \\
\text { media messages. }\end{array}$ & 0.948 \\
\hline
\end{tabular}

Our rotated component matrix shows that our first component is measured by Item 4 , therefore, we interpret component 1 as "social media confidence". This is the underlying trait measured by Item 4 . After interpreting all components in a similar fashion, we arrived at the following descriptions: Component 1 -social media confidence; Component 2 -social media communication process understanding; Component 3-social media literacy; Component 4-social media content impact awareness.

\section{Discussion}

The current worldwide social distancing situation has moved much of youth energy into the digital realm, and now more than ever new research is needed for understanding the rising phenomenon of digital hate speech which occurs in the majority of social media platforms.

As a key point, we would like to highlight further how culture and social sustainability mediatization [53] are changing everyday behavior, considering the results of the research. These days, the digital environment is an important force in culturalization and socialization and, last but not least, mediatization tied up with the terms of media democratization and fighting against fake news [54-57] and online hate speech [58]. This provides obvious benefits in terms of quicker access to a lot of information, which ensures that people are well educated and more able to access critical thinking [59] and digital literacy $[60,61]$, they are able to take more informed decisions and act upon, solve a complex range of problems [62], and also seek medical advice [63]. With all these technological advances, the problem of social media literacy and social media context awareness has not been adequately addressed so far, and nor had been conceptualized so far as a social sustainable research topic.

The present research was focused on defining and measuring the social media context awareness comprehended as an emerging digital skill referring to the understanding of the digital environment in which a specific social media event takes place, acknowledging the impact that the perceived social media context has over the observer, rationalizing the social media informational undergoing process, and owning confidence for social media acting.

With the purpose of designing and validating a new scale of social media context awareness (SMCA), we have operationalized the emerging digital skill as a confluence between four key components: Social media literacy, social media communication process understanding, social media content impact awareness, and social media confidence.

A reliability analysis was carried out $(\mathrm{N}=206)$ on the social media context awareness scale comprising four items referring to social media literacy "I' $m$ able to access the information and content I want on social media" ( $\mathrm{m}=3.79, \mathrm{SD}=1)$, social media communication process understanding "I understand how people create and spread messages on social media" ( $\mathrm{m}=3.77, \mathrm{SD}=0.9)$, social media content impact awareness "I understand the role social media websites/apps play in shaping the information and content I see" $(\mathrm{m}=3.88, \mathrm{SD}=1)$, and social media confidence "I'm confident 
creating and sharing my own social media messages" $(\mathrm{m}=3.45, \mathrm{SD}=1)$. Cronbach's alpha coefficient proves that the questionnaire achieves reasonable precision, $\alpha=0.87$. Our rotated component matrix showed that the first component is measured by Item 4 , therefore, we interpret component 1 as "social media confidence". After interpreting all components in a similar fashion, we arrived at the following descriptions: Component 1 -social media confidence; Component 2 -social media communication process understanding; Component 3-social media literacy; Component 4-social media content impact awareness. In conclusion, results obtained support the statistical robustness of our SMCA scale (Appendix A).

Amongst the limitations of this research, we can enumerate the targeted population as being young and adult educated individuals from four different countries spending much time over the internet. Being an uncontrolled online exploratory investigation, responses were chosen based on convenience sampling, thus particular characteristics such as minority respondents, uneducated individuals, and vulnerable group respondents have not been taken into consideration. Particular attention must be given to these groups in further investigations focused on social media context awareness. There is more research needed on additional items factor loading investigation to increase the validity of the SMCA scale. Since there are no other measures employed in this research to help establish the preliminary short version of the social media context awareness scale, the results might be limited and additional data should be collected in order to establish that this is a strong measure of social media context awareness.

\section{Conclusions}

The main conclusion of this research is that social media context awareness is an emerging digital competency that can be empirically measured and then taught to individuals who have not developed this vital skill, for a sustainable understanding of the socio-digital environment.

When actively handling the flow of information, it is obvious that no one in this digital world can control the flow of information. One of the features that separates social media from the media is the independence of individual access to knowledge, in this scenario social media consumers chose whatever content and information they want.

Similar to traditional newspapers, TV news, for example, a culture wants to consume the news broadcast by a television network. Meanwhile, internet account owners can choose to read the information they want in social media, and they are also able to choose which information is going to be shared. It is not simple though, since it applies to a social network user's personal experience.

Of course, with quick access to social media, the sharing of information can work very rapidly [64]. Some information can be easily disseminated and exchanged online. Preventive action is required upon that information. Nevertheless, we must then figure out if the material just reported is right or not, whether or not the sequence of events correlates to facts, or the context of the material is recently obtained.

More specifically, similar to other big campaigns, media literacy would begin at a local level when parents, educators, and informed people come to notice that if media were to play a crucial position as a child tutor, children would also need to find a means of filtering through information such that wise decisions would be made in compliance with appropriate cultural norms. Formal schooling, not simply repression or power, is a way of making young people consider their decisions and begin to challenge the ideals portrayed by the media.

Although globalization has helped foreign culture, protection against the proliferation of knowledge on social media is also required for the sake of young people's brains, as young people, particularly students, are highly interested in new social media content. There would be no issue because all the information disseminated is suitable for young people. However, considering that world news often includes topics such as extremism, hedonistic habits and, therefore, a certain atmosphere of power projection diplomacy that can easily influence the perceptions of young people, a certain attempt must be taken to ensure that all material and knowledge available to young people is secure. 
There is no system to ensure that more intervention is taken without encouraging the youth themselves. Social media awareness will be an important response to this, because it can allow young people to be conscious of the effects of social networking and new knowledge generated by globalization. Thereby, we should deliberately control the flow of knowledge and effectively engage in the development of laws regarding the usage of digital technologies, to avoid the degradation of the perceptions of our young people by poor material. It is also really necessary to ensure that the young generation is completely capable of analyzing and sorting the information supplied to them by enhancing their social media literacy skills. In addition, how can this desiderate be attained if not assessing firstly the individuals' level of social media context awareness?

Provided the technological and socio-cultural features of the digital media, people are already able to convey adequate social media literacy $[65,66]$. Based on the two-continue (consuming-prosuming and functional-critical) framework of Chen et al. [66], we suggested four fine-grained indexes to represent the concept of social media context awareness. Further research can find alternate ways of analyzing the construction element of social media context awareness.

Thus, the aim of a digital context awareness scale is needed to self-rate the digital literacy level.

We anticipate the social media context awareness concept to be a meaningful mediator in relationships regarding the use of digital technology and its impact on the overall wellbeing indexes of individuals and collectivities. Validation in larger samples and environments is needed to further test the robustness of the social media context awareness scale. This preliminary investigation brings an evidence base for the assessment of this new emerging skill. More in-depth research is needed for further testing and validating this scale on a large pool of items, in order to more precisely determine the four-factor design loading.

Author Contributions: Conceptualization, D.R., E.D., and T.D.; methodology, D.R., E.D., and T.D.; software, D.R. and E.D.; validation, D.R., E.D., and T.D.; formal analysis, D.R. and T.D.; investigation, D.R., E.D., T.D., and R.L.; resources, V.B., R.L., and D.R.; data curation, D.R. and E.D.; writing-original draft preparation, D.R. and V.E.B.; writing-review and editing, T.D., R.L., and D.R.; visualization, E.D. and R.L.; supervision, V.B. and R.L. All authors have equally contributed to this manuscript. All authors have read and agreed to the published version of the manuscript.

Funding: This research received external funding from Erasmus+ Hate's Journey, project ID: 2018-2-ES02KA205-011733.

Conflicts of Interest: The authors declare no conflict of interest.

\section{Appendix A}

Table A1. Social Media Context Awareness Scale SMCA (Rad, D., Balas, E.V., Lile, R., Demeter, E., Dughi, T., Rad, G., 2020).

\begin{tabular}{|c|c|c|c|c|c|c|}
\hline No. & Item & $\begin{array}{l}1 \text { Strongly } \\
\text { Disagree }\end{array}$ & $\begin{array}{c}2 \\
\text { Disagree }\end{array}$ & $\begin{array}{l}3 \text { Neither } \\
\text { Agree Nor } \\
\text { Disagree }\end{array}$ & $\begin{array}{c}4 \\
\text { Agree }\end{array}$ & $\begin{array}{l}5 \text { Strongly } \\
\text { Agree }\end{array}$ \\
\hline 1 & $\begin{array}{l}\text { I am able to access the information and } \\
\text { content I want on social media. }\end{array}$ & & & & & \\
\hline 2 & $\begin{array}{l}\text { I understand how people create and } \\
\text { spread messages on social media. }\end{array}$ & & & & & \\
\hline 3 & $\begin{array}{l}\text { I understand the role social media } \\
\text { websites/apps play in shaping the } \\
\text { information and content I see. }\end{array}$ & & & & & \\
\hline 4 & $\begin{array}{l}\text { I am confident creating and sharing my } \\
\text { own social media messages. }\end{array}$ & & & & & \\
\hline
\end{tabular}


Each of the four items refers to a component of the social media context awareness: Component 1-social media confidence (Item 4); Component 2—social media communication process understanding (Item 2); Component 3-social media literacy (Item 1); Component 4-social media content impact awareness (Item 3).

The final score is obtained by the sum of the results of all four items. A score lower than 10 (inclusively), represents low social media context awareness skills and a score higher than 10, represents high social media context awareness skills.

\section{References}

1. Schilit, B.; Theimer, M. Disseminating active map information to mobile hosts. Netw. IEEE 1994, 8, 22-32. [CrossRef]

2. Ryan, N.S.; Pascoe, J.; Morse, D.R. Enhanced Reality Fieldwork: The Context-Aware Archaeological Assistant, Computer Applications in Archaeology 1997; ser. British Archaeological Reports; Gaffney, V., van Leusen, M., Exxon, S., Eds.; Tempus Reparatum: Oxford, UK, 1997.

3. Abowd, G.D.; Dey, A.K.; Brown, P.J.; Davies, N.; Smith, M.; Steggles, P. Towards a Better Understanding of Context and Context-Awareness. In Proceedings of the 1st International Symposium on Handheld and Ubiquitous Computing (HUC '99), Karlsruhe, Germany, 27-29 September 1999; Springer-Verlag: London, UK, 1999; pp. 304-307. Available online: http://dl.acm.org/citation.cfm?id=647985.743843 (accessed on 20 February 2020).

4. Dey, K.; Abowd, G.D.; Salber, D. A conceptual framework and a toolkit for supporting the rapid prototyping of context-aware applications. Hum. Comput. Interact. 2001, 16, 97-166. [CrossRef]

5. García, Ó.; Alonso, R.S.; Prieto, J.; Corchado, J.M. Energy Efficiency in Public Buildings through Context-Aware Social Computing. Sensors 2017, 17, 826. [CrossRef] [PubMed]

6. Chang, J.; Yao, W.; Li, X. A Context-Aware S-Health Service System for Drivers. Sensors 2017, 17, 609. [CrossRef] [PubMed]

7. Hu, P.; Indulska, J.; Robinson, R. An autonomic context management system for pervasive computing. In Proceedings of the 2008 Sixth Annual IEEE International Conference on Pervasive Computing and Communications (PerCom), Hong Kong, China, 17-21 March 2008; pp. 213-223. [CrossRef]

8. Benkler, Y. The Wealth of Networks; Yale University Press: New Haven, CT, USA, 2006.

9. Fuchs, C. Social Media: A Critical Introduction; Sage: London, UK, 2014.

10. Kane, G.C.; Alavi, M.; Labianca, G.; Borgatti, S.P. What's different about social media networks? A framework and research agenda. MIS Q. 2014, 38, 275-304. [CrossRef]

11. Parra-López, E.; Gutiérrez-Taño, D.; Diaz-Armas, R.J.; Bulchand-Gidumal, J. Travellers 2.0: Motivation, opportunity and ability to use social media. In Social Media in Travel, Tourism and Hospitality: Theory, Practice and Cases; Routledge: London, UK; Taylor \& Francis Group: New York, NY, USA, 2012; pp. 171-187.

12. Parra, C.; Moulaert, F. Why sustainability is so fragilely social? In Strategic Spatial Projects: Catalysts for Change; Oosterlynck, S., Van den Broeck, J., Albrechts, L., Moulaert, F., Verhetsel, A., Eds.; Routledge: London, UK, 2010; pp. 242-256.

13. Parra, C.; Moulaert, F. La nature de la durabilité sociale: Vers une lecture socioculturelle du développement territorial durable. Développement Durable et Territories 2011, 2. [CrossRef]

14. Hjarvard, S. The mediatization of religion: Theorising religion, media and social change. Cult. Relig. 2011, 12, 119-135. [CrossRef]

15. Lövheim, M.; Lynch, G. The mediatisation of religion debate: An introduction. Cult. Relig. 2011, 12, 111-117. [CrossRef]

16. Schofield Clark, L. Considering religion and mediatisation through a case study of J+K's big day (The J K wedding entrance dance): A response to Stig Hjarvard. Cult. Relig. 2011, 12, 167-184. [CrossRef]

17. Couldry, N.; Hepp, A. Conceptualizing Mediatization: Contexts, Traditions, Arguments. Commun. Theory 2013, 23, 191-202. [CrossRef]

18. Bratosin, S. La médialisation du religieux dans la théorie du post néo-protestantisme. Soc. Comp. 2016, 63, 405-420. [CrossRef] 
19. Gomes, P.G. Mediatization: A Concept, Multiple Voices (La Médiatisation: Un Concept, Des Voix Multiples). ESSACHESS-J. Commun. Stud. 2016, 9, 18. Available online: https://ssrn.com/abstract=2926854 (accessed on 20 February 2020).

20. Lövheim, M.; Lundmark, E. Gender, Religion and Authority in Digital Media. Essachess J. Commun. Stud. 2019, 12, 23-38.

21. Livingstone, S. On the Mediation of Everything: Ica Presidential Address 2008. J. Commun. 2009, 59, 1-18. [CrossRef]

22. Rad, D.; Demeter, E. Youth Sustainable Digital Wellbeing. Postmod. Open. 2019, 10, 104-115. [CrossRef]

23. Rad, D.; Dixon, D.; Rad, G. Digital Outing Confidence as a Mediator in the Digital Behaviour Regulation and Internet Content Awareness Relationship. BRAIN 2020, 11, 84-95. [CrossRef]

24. Buckingham, D. Defining Digital Literacy. In Medienbildung in Neuen Kulturräumen; Bachmair, B., Ed.; VS-Verlag für Sozialwissenschaften: Wiesbaden, Germany, 2010.

25. Eshet-Alkalai, Y. Digital literacy: A conceptual framework for survival skills in the digital era. J. Educ. Multimed. Hypermedia 2004, 1391, 93-106.

26. Gilster, P. Digital fusion: Defining the intersection of content and communications. In Digital Literacies for Learning; Martin, A., Madigan, D., Eds.; Facet Publishing: London, UK, 2006; pp. 42-50.

27. Willams, P.; Minnian, A. Exploring the challenges of developing digital literacy in the context of special educational needs communities. In Change and Challenge: Information Literacy for the 21st Century; Andretta, S., Ed.; Auslib Press: Adelaide, Australia, 2007.

28. Hargittai, E. Survey measures of web-oriented digital literacy. Soc. Sci. Comput. Rev. 2005, 23, 371-379. [CrossRef]

29. Burniske, R.W. Literacy in the Digital Age, 2nd ed.; Corwin Press: Thousand Oaks, CA, USA, 2007.

30. Martin, A.; Madigan, D. Digital Literacies for Learning; Facet Publishing: London, UK, 2006.

31. Bawden, D.; Robinson, L. Promoting literacy in a digital age: Approaches to training for information literacy. Learn. Publ. 2002, 15, 297-301. [CrossRef]

32. Bawden, D. Information and digital literacies: A review of concepts. J. Doc. 2001, 57, 218-259. [CrossRef]

33. Pilerot, O. Information literacy: An overview. In Digital Literacies for Learning; Martin, A., Madigan, D., Eds.; Facet Publishing: London, UK, 2006; pp. 820060-820088.

34. Livingstone, S. Developing social media literacy: How children learn to interpret risky opportunities on social network sites. Communications 2014, 39, 283-303. [CrossRef]

35. June, A. What can we learn from Facebook activity? using social learning analytics to observe new media literacy skills. In Proceedings of the Third International Conference on Learning Analytics and Knowledge (LAK '13), Leuven, Belgium, 8-12 April 2013; Association for Computing Machinery: New York, NY, USA, 2013; pp. 135-144.

36. Cohen, J.N.M.; Mihailidis, P. Exploring Curation as a core competency in digital and media literacy education. J. Interact. Media Educ. 2013, (Part 2). [CrossRef]

37. Gammon, M.A.; White, J. (Social) media literacy: Challenges and opportunities for higher education. In Educating Educators with Social Media (Cutting-Edge Technologies in Higher Education); Wankel, C., Ed.; Emerald Group Publishing Limited: Bingley, UK, 2011; Volume 1, pp. 329-345. [CrossRef]

38. Pfaff-Rüdiger, S.; Riesmeyer, C. Moved into action. Media literacy as social process. J. Child. Media 2016, 10, 164-172. [CrossRef]

39. Ye, X.; Zhao, B.; Nguyen, T.H.; Wang, S. Social Media and Social Awareness. In Manual of Digital Earth; Guo, H., Goodchild, M., Annoni, A., Eds.; Springer: Singapore, 2020.

40. Levordashkaa, A.; Utzab, S. Ambient awareness: From random noise to digital closeness in online social networks. Comput. Hum. Behav. 2016, 60, 147-154. [CrossRef] [PubMed]

41. Prensky, M. Digital natives, digital immigrants Part 1. Horizon 2001, 9, 1-6. [CrossRef]

42. Kontos, E.; Blake, K.D.; Chou, W.Y.S.; Prestin, A. Predictors of eHealth usage: Insights on the digital divide from the health information national trends survey 2012. J. Med. Internet Res. 2014, 16, e172. [CrossRef]

43. Cann, A.; Dimitriou, K.; Hooley, T. Social Media: A Guide for Researchers; Research Information Network: London, UK, 2011.

44. Kalaivani, S.; Bakkiyalashmi, E. A Study of Awareness and Utilization of Social Media By, B.Ed Trainees. Int. J. Multidiscip. Res. Mod. Educ. 2017, 1, 207-208. 
45. Student Engagement and Participation: Concepts, Methodologies, Tools, and Applications; IGI Global: Hershey, PA, USA, 2017.

46. Potoskya, D.; Bobkob, P. The computer understanding and experience scale: A self-report measure of computer experience. Comput. Hum. Behav. 1998, 142, 37-348. [CrossRef]

47. Strader, T.J.; Fichtner, J.R.; Bartlett, G.D.; Simpson, L.A. Online and Offline Content Piracy Activities: Characteristics and Ethical Perceptions. Int. J. Technoethics 2014, 2, 22-36. [CrossRef]

48. Preeshl, A. Reframing Acting in the Digital Age; Routlege: London, UK, 2019.

49. Albarracín, D.; Wyer, R.S., Jr. The cognitive impact of past behavior: Influences on beliefs, attitudes, and future behavioral decisions. J. Personal. Soc. Psychol. 2000, 79, 5-22.

50. Tudor, M.A.; Bratosin, S. French Media Representations towards Sustainability: Education and Information through Mythical-Religious References. Sustainability 2020, 12, 2095.

51. Brown, K.W.; Ryan, R.M. The benefits of being present: Mindfulness and its role in psychological well-being. J. Personal. Soc. Psychol. 2003, 84, 822-848. [CrossRef] [PubMed]

52. Carlson, L.E.; Brown, K.W. Validation of the Mindful Attention Awareness Scale in a cancer population. J. Psychosom. Res. 2005, 58, 29-33. [CrossRef] [PubMed]

53. Demeter, E.; Rad, D. Global Life Satisfaction and General Antisocial Behavior in Young Individuals: The Mediating Role of Perceived Loneliness in Regard to Social Sustainability-A Preliminary Investigation. Sustainability 2020, 12, 4081. [CrossRef]

54. Bratosin, S.; Gomes, P.-D.; Neto, F.A. Mediatization of religion and power. Ess. J. Commun. Stud. 2017, 10, 5-203.

55. Bratosin, S.; Jauffret, M. Le mythe politique français de la laïcité: Foi et sens politique. In Politique et Religion au Défi de la Communication Numérique; Tudor, M.A., Clitan, G., Grilo Marat, M., Eds.; l'Harmattan: Paris, France, 2018; pp. 41-55.

56. Bratosin, S.; Tudor, M.A. Religion(s), Laïcité(s) et Société(s) au Tournant des Humanités Numériques; Iarsic: Les Arcs, France, 2016.

57. Tudor, M.A.; Bratosin, S. The Romanian Religious Media Landscape: Between Secularization and the Revitalization of Religion. J. Rel. Media Digit. Cult. 2018, 7, 223-250. [CrossRef]

58. Roman, A.; Rad, D.; Egerau, A.; Dixon, D.; Dughi, T.; Kelemen, G.; Balas, E.; Rad, G. Physical Self-Schema Acceptance and Perceived Severity of Online Aggressiveness in Cyberbullying Incidents. J. Interdiscip. Stud. Educ. 2020, 9, 100-116. [CrossRef]

59. Straková, Z.; Cimermanová, I. Critical Thinking Development-A Necessary Step in Higher Education Transformation towards Sustainability. Sustainability 2018, 10, 3366. [CrossRef]

60. Kim, H.J.; Hong, A.J.; Song, H.D. The Relationships of Family, Perceived Digital Competence and Attitude, and Learning Agility in Sustainable Student Engagement in Higher Education. Sustainability 2018, 10, 4635. [CrossRef]

61. Abad-Segura, E.; González-Zamar, M.D.; Luque de la Rosa, A.; Gallardo-Pérez, J. Gestión de la economía digital en la educación superior: Tendencias y perspectivas futuras. Campus Virtuales 2020, 9, 57-68.

62. Franco, A.; Marques Vieira, R.; Tenreiro-Vieira, C. Educating for critical thinking in university: The criticality of critical thinking in education and everyday life. ESSACHESS J. Commun. Stud. 2018, 11, 131-144.

63. Grosjean, S.; Bonneville, L.; Redpath, C. The Design Process of an mHealth Technology: The Communicative Constitution of Patient Engagement through a Participatory Design Workshop. ESSACHESS J. Commun. Stud. 2019, 12, 5-27.

64. Daneels, R.; Vanwynsberghe, H. Mediating social media use: Connecting parents' mediation strategies and social media literacy. Cyberpsychology 2017, 11, 5. [CrossRef]

65. Lin, T.-B.; Li, J.-Y.; Deng, F.; Lee, L. Understanding New Media Literacy: An Explorative Theoretical Framework. Educ. Technol. Soc. 2013, 16, 160-170.

66. Chen, D.-T.; Wu, J.; Wang, Y.-M. Unpacking new media literacy. J. Syst. Cybern. Inform. 2011, 9, 84-88.

(C) 2020 by the authors. Licensee MDPI, Basel, Switzerland. This article is an open access article distributed under the terms and conditions of the Creative Commons Attribution (CC BY) license (http://creativecommons.org/licenses/by/4.0/). 